\title{
LETTER
}

\section{Cough - another important factor in extubation readiness in critically ill patients}

\author{
Zong-Yu Wang* and Yu Bai \\ See related research by Liu et al., http://ccforum.com/content/16/4/R143
}

Ling Liu and colleagues [1] found that critically ill patients who fail weaning have impaired ability to convert neuromuscular activity into tidal ventilation, highlighting the effect of diaphragm weakness on weaning and extubation from mechanical ventilation. However, it is noteworthy that the insufficient cough strength greatly contributes to failed extubation in clinical practice as well, particularly in patients with acute cervical cord injury, or who have undergone major thoracic or abdominal surgery. Some intubated patients with inadequate cough strength can successfully pass the spontaneous breathing trial, but nevertheless might still experience extubation failure afterwards. It is difficult for them to clear secretions in airways due to the inability to cough, which leads to increased risk of atelectasis and respiratory infection. Weak cough can be attributable to expiratory muscle dysfunction, inspiratory muscle weakness, and so on; however, expiratory muscle function is crucial for effective cough [2]. The major expiratory muscles include the muscles of the anterolateral wall of the abdomen, the expiratory intercostal muscle, and the triangularis sterni [3]. The neuro-ventilatory efficiency of these muscles, however, cannot be assessed by diaphragm electrical activity.

Expiratory muscle strength became a focus of interest for estimating cough strength. Cough peak expiratory flow was used to evaluate cough reflex, which was considered an indicator for predicting successful extubation of patients who pass a spontaneous breathing trial [4]. In summary, the mechanical ventilation withdrawal process relates not only to the inspiratory driving force driven predominantly by the diaphragm, but also to cough strength, which involves the expiratory muscles.

Competing interests

The authors declare that they have no competing interests.

\section{Authors' contributions}

Conceived by Z-YW and YB. Z-YW and YB drafted the manuscript. Both authors have read and approved the final manuscript.

Published: 13 November 2012

\section{References}

1. Liu L, Liu H, Yang Y, Huang Y, Liu S, Beck J, Slutsky AS, Sinderby C, Qiu H: Neuroventilatory efficiency and extubation readiness in critically ill patients. Crit Care 2012, 16:R143.

2. Epstein SK: Decision to extubate. Intensive Care Med 2002, 28:535-546.

3. Fujiwara $T$, Hara Y, Chino N: Expiratory function in complete tetraplegics: study of spirometry, maximal expiratory pressure, and muscle activity of pectoralis major and latissimus dorsi muscles. Am J Phys Med Rehabil 1999, 78:464-469.

4. Su WL, Chen YH, Chen CW, Yang SH, Su CL, Perng WC, Wu CP, Chen JH: Involuntary cough strength and extubation outcomes for patients in an ICU. Chest 2010, 137:777-782.

doi:10.1186/cc11817

Cite this article as: Wang ZY, Bai Y: Cough - another important factor in extubation readiness in critically ill patients. Critical Care 2012, 16:461.

*Correspondence: wangzy1976@126.com

Department of Intensive Care Unit, Peking University Third Hospital,

49 North Garden Road, Haidian District, Beijing, China 